\title{
VIDEO ANIMASI LAYANAN MASYARAKAT BAHAYA MEDIA SOSIAL TERHADAP REMAJA
}

\author{
${ }^{1}$ Didi Putra Hariyadi, ${ }^{2}$ Danang Tejo Kumoro \\ ${ }^{1}$ Mahasiswa ${ }^{2}$ Dosen Program Studi Teknik Informatika, STMIK Bumigora Mataram \\ JL. Ismail Marzuki Mataram, NTBTelp (0370)-634 498, Fax (0370) 638369 \\ ${ }^{1}$ Dhidiputra76@gmail.com, ${ }^{2}$ danangmoro@gmail.com
}

\begin{abstract}
ABSTRAK
Berkembangnya teknologi yang semakin canggih di era globalisasi saat ini berdampak langsung bagi masyarakat Indonesia. Sebelum perkembangan tersebut nampak jelas di dunia ini, tidak banyak masyarakat yang mengenal berbagai macam media telekomunikasi seperti internet. Berbeda dengan zaman sekarang di mana sebagian masyarakat bahkan masyarakat menengah ke bawah, sudah mengenal teknologi komunikasi seperti internet yang di dalamnya terdapat konten-konten seperti media sosial. Dalam penelitian ini penulis menjadikan Lembaga Perlindungan Anak Nusa Tenggara Barat atau LPA NTB sebagai tempat penelitian, penulis mendapatkan data dari LPA untuk dijadikan konten dalam Video Animasi Layanan Masyarakat Bahaya Media Sosial Terhadap Remaja, video ini berfungsi sebagai media pengembangan sosialisasi LPA yang selama ini melakukan sosialisasi secara manual seperti menyebarkan pamflet dan sebagainya. Hasil dari penelitian penulis dalam pembuatan video animasi layanan masyarakat bahaya media sosial terhadap remaja, dapat mengembangkan media sosialisasi, khususnya dalam sosialisasi bahaya media sosial.

Kesimpulan penulisan penelitian ini adalah pembutan video animasi layanan masyarakat bahaya media sosial terhadap remaja dapat diterima sebagai media sosialisasi yang berbentuk video animasi.
\end{abstract}

Kata Kunci : Mengembangkan,Video Animasi, LPA NTB, Sosialisasi, Media Sosial.

\section{PENDAHULUAN}

Berdasarkan data di Departemen Komunikasi dan Informasi [3], dapat diketahui bahwa Indonesia saat ini mencapai 63 juta orang. Dari angka tersebut, 95 persennya menggunakan internet untuk mengakses jejaring sosial.

Sejak dirilisnya situs media sosial seperti facebook, twitter, instagram, dan jenis media sosial lainnya. Dampak yang diakibatkan sungguh luar biasa karena secara mendasar mampu mengubah sikap dan perilaku bahkan norma-norma dalam kehidupan sosial manusia [2]. Data dari "Dirjen Sumberdaya Perangkat Pos dan Informatika Kemen Kominfo", menyatakan bahwa jumlah pengguna internet di Indonesia menguasai Asia sebesar 22,4 persen. Indonesia merupakan negara peringkat ketiga di Asia untuk jumlah pengguna internet. Penggunanya sebanyak 55 juta orang dari 245 juta penduduk Indonesia. Jumlah pengguna ini semakin meningkat terutama pada usia muda mulai dari 15-20 tahun dan 10-14 tahun. Indonesia juga tercatat sebagai negara kelima terbesar pengguna Twitter di bawah Inggris. Untuk situs jejaring tercatat sebanyak 44,6 juta pengguna Facebook dan sebanyak 19,5 juta pengguna Twitter di Indonesia [3].

Berdasarkan data dari Kompas.com, seorang wanita menjadi korban pelecehan oleh 4 pria yang salah satu pria di kenal lewat media sosial facebook [4], dan berdasarkan data dari Viva.co.id, bahwa jejaring sosial facebook digunakan untuk menjual barang hasil curian, pelaku tersebut menjual di salah satu forum jual beli online Mataram Lombok [5]. Berdasarkan wawancara penulis dengan pihak LPA NTB yang di wakili oleh Khaerus Febryan Fitrahadi, $\mathrm{SH}, \mathrm{MH}$ selaku bagian pelayanan dan penanganan kasus, bahwa beberapa kasus pelecehan [red], terhadap anak berawal dari perkenalan lewat media sosial seperti facebook.

Dengan melihat fakta di atas, tidak sedikit para remaja yang terjerumus ke dalam hal yang negatif akibat media sosial, faktor utama masalahnya adalah kurangnya pemahaman masyarakat saat ini terhadap batas-batas pergaulan dalam sosial media. Berdasarkan latar 
belakang tersebut, maka penulis membuat judul

"Video Animasi Layanan Masyarakat Bahaya Media Sosial Terhadap Remaja" dengan video animasi layanan masyarakat di harapkan dapat mengembangkan media sosialisasi Lembaga Perlindungan Anak NTB.

\section{METODOLOGI}

Dalam metode penelitian, penulis menggunakan metode pengumpulan data yang terdiri dari observasi, wawancara, studi pustaka dan kuesioner, penulis menggunakan kuesioner untuk mendapatkan hasil dari persepsi dari responden, dan penulis menggunakan skala likert untuk mempresentasikan berapa persen tingkat keberhasilan dari penelitian yang penlis buat. Di metode pengembangan multimedia penulis menggunakan metode luther sutopo [1].

\section{Konsep}

Penulis menentukan tujuan yaitu Lembaga Perlidungan Anak Nusa Tenggara Barat, untuk digunakan sebagai media pengembangan bahan sosialisasi kepada masyarakat mengenai bahaya media sosial. Dan penulis menyusun naskah konsep dari video animasi, naskah konsep ini dibutuhkan untuk mempermudah pembuatan storyboard pada tahap desain, berikut naskah konsepnya :

Scene 01: Menampilkan logo LPA NTB yang menjadi tempat penelitian penulis dan judul "Penelitian Bahaya Media Sosial"

Audio : Bahaya media sosial

Story : Logo lembaga perlindungan anak NTB muncul di bawah tulisan penelitian bahaya media sosial.

Durasi : $00.00-00.03$

Scene 02: Menampilkan reporter pembawa berita

Audio : Musik latar belakang

Story : Reporter pembawa berita muncul di sebelah kanan dan melambaikan tangan

Durasi : $00.04-00.07$

Scene 03: Pembawa acara mulai membuka berita yang dibawakan dengan background pengguna media sosial.

Audio : Musik latar belakang, dan vokal, media sosial telah menjadi suatu kebutuhan sehari-hari termasuk dalam cara baru berkomunikasi dan berbagi. Selain memberikan kemudahan bagi pengguna, media sosial juga memiliki dampak negatif bagi penggunanya. Dari mulai bahaya sosial, personal, hingga finansial.

Story : Pembawa berita memegang mic untuk membawakan berita dengan latar belakang pengguna media sosial yang lagi sibuk bermain dengan smartphone
Vol.1 No.1 (Mei) 2019, Hal 1-12

dan pc, dan lelaki yang dengan mimik muka yang tidak ada niat beraktifitas karena kelelahan. Di samping kiri ada tulisan LPA NTB judul berita bahaya media sosial.

Durasi : $00.08-00.25$

Scene 04: Background dari reporter hilang

Audio : Musik, vokal, semua bisa ditimbulkan oleh media sosial jika tidak bijak menggunakannya. Dan beberapa masalah yang terjadi di Pulau Nusa Tenggara Barat khususnya pulau Lombok, akan saya liput dalam berita kali ini.

Story : Title judul dan tulisan reporter di sebelah kiri berangsur hilang dan reporter mulai memasuki sesi liputan

Durasi : :00.26-00.41

Scene 05: Menampilakan logo Kompas.com

Audio : Musik, vokal, yang pertama, berdasarkan data Kompas.com

Story : Muncul berita online Kompas.com beserta logo dari arah kiri ke kanan

Durasi : $00.42-00.45$

Scene 06: Menampilkan animasi kejahatan media sosial facebook

Audio : Musik, vokal, seorang wanita diperkosa oleh 4 pria yang salah satu pria di kenal lewat media sosial Facebook.

Story : Seorang wanita sedang bermain sosial media di depan pc, lelaki jahat tiba tiba muncul 1 persatu sampai berjumlah 4 orang, dari scene tersebut penulis menyatakan bahwa secara tidak langsung dengan bermain sosial media secara tidak benar dapat menjerumuskan penggunannya.

Durasi : $00.46-00.52$

Scene 07: Menampilkan logo Viva.co.id

Audio : Musik, vokal, kedua, menurut Viva.co.id.

Story : Dari sisi kiri muncul berita online viva.co.id dengan logo dari arah kiri ke kanan

Durasi : $00.53-00.55$

Scene 08: Memaparkan animasi kejahatan media sosial facebook yang menjual barang hasil curian di group facebook

Audio : Musik, vokal, jejaring sosial Facebook banyak digunakan untuk menjual barang hasil curian, pelaku tersebut menjual di salah satu forum jual beli online Mataram,Lombok.

Story : Muncul gambar-gambar seperti laptop, smartphone, kardus yang bernilai dan lambang uang yang mewakili terjadinya 
penjualan barang curian dengan

Vol.1 No.1 (Mei) 2019, Hal 1-12

memanfaatkan jejaring facebook.

Durasi : :00.56-01.05

Scene 09: Menampilkan logo Lembaga Perlindungan Anak Nusa Tenggara Barat

Audio : Musik, vokal, ketiga, berdasarkan wawancara dengan pihak LPA NTB,

Story : Dari sisi kiri muncul tulisan Lembaga Perlindungan Anak NTB beserta logo.

Durasi : :01.06-01.16

Scene 10: Menampilkan kejahatan akibat berlebihan menggunakan media sosial

Audio : Musik, vokal, beberapa kasus pemerkosaan berawal dari perkenalan lewat media sosial Facebook. Terjadi ketika kedua individu berpacaran.

Story : Muncul gambar hati yang melambangkan individu yang sedang berpacaran, sebelah kiri wanita dan sebelah kanan pria

Durasi : :01.17-01.25

Scene 11: Logo media sosial beetalk

Audio : Musik, vokal, dan saat setelah individu tersebut tidak berpacaran, laki-laki menyebar foto-foto wanita yang tidak senonoh lewat akun media sosialnya.

Story : Gambar hati yang mewakili individu yang berpacaran tersebut terbelah menjadi 2 bagian yang menunjukan bahwa hubungan antara individu tersebeut berakhir.

Durasi : :01.26-01.31

Scene 12: Menampilkan logo media sosial beetalk

Audio : Musik, vokal, keempat, begitu pula dengan hasil penulusuran lewat media sosial Beetalk.

Story : Dari arah tengah muncul logo lebah yang menjadi logo dari salah satu media sosial yang ditelusuri oleh penulis.

Durasi : :01.32-01.38

Scene 13: Menampilkan individu yang mengakses smartphone yang menayangkan caption seperti "lagi butuh uang", "minat chat".

Audio : Musik, vokal, didalamnya terdapat banyak akun yang menjajakan diri dengan modus memasang foto seksi lalu menulis beberapa caption, diantaranya "Lagi butuhuang" atau "Minat, chat".

Story : Smartphone mewakili orang yang sedang mengakses media sosial beetalk, dan muncul tulisan atau caption "lagi butuh uang", "minat chat".

Durasi : :01.39-01.50

Scene 14: Menampilkan gambar smartphone dengan pisau
Audio

: Musik, vokal, status-status tersebut digunakan untuk menarik minat dari lawan jenis untuk memulai chat yang berujung pada seks bebas, perdagangan manusia, dan berbagai macam tindakan kriminal.

Story : Di sebelah kiri ada gambar smartphone dan di sebelah kanan gambar pisau yang melambangkan kejahatan.

Durasi : :01.51-01.59

Scene 15: Menayangkan logo bigolive

Audio : Musik, vokal, kelima, bigolive, bigolive adalah suatu aplikasi yang memuat banyak konten- konten negatif.

Story : Dari arah tengah muncul gambar hewan yang mirip dinosaurus yang mewakili media sosial Bigolive.

Durasi : :01.60-02.07

Scene 16: Menayangkan individu yang mengakses bigolive

Audio : Musik, vokal, Karena penggunanya atau penyiar di dominasi oleh perempuan..

Story : Dari sisi kanan muncul smartphone yang di layarnya ada gambar seorang wanita dan tangan yang memegang smartphone seolah-olah sedang menonton live streaming

Durasi : $02.08-02.12$

Scene 17: Menampilkan logo smartphone, uang logam dan berlian

Audio : Musik, vokal, yang melakukan live streaming dan memamerkan bagianbagian tubuh yang seharusnya tidak boleh diperlihatkan, bahkan joget secara erotis. BigoLive digunakan untuk mencari uang dengan cara mengumpulkan diamond yang diberikan oleh pengunjung channel broadcast.

Story : Smartphone yang menampilkan live streaming gambar erotis dan di sisi kiri uang dan berlian yang didapatkan dari memamerkan bagian tubuh tertentu.

Durasi : :02.13-02.28

Scene 18: Menampilkan tulisan cara menggunakan media sosial.

Audio : Musik, vokal, setelah menyimak liputan bahaya media sosial, saya akan mengenalkan tata cara dalam menggunakan media sosial sebagai berikut.

Story : Reporter selesai membawakan berita mengenai bahaya media sosial yang sudah terjadi dan akan menerangkan sedikit cara menggunakan media sosial. 
Durasi : 02.29-02.34

Vol.1 No.1 (Mei) 2019, Hal 1-12

Scene 19: Menampilkan gambar laptop dan gambar yang berkaitan dengan data pribadi dan tulisan yang memperingatkan jangan memberikan data pribadi kepada orang yang tidak dikenal.

Audio : Musik, vokal, jangan memberikan data pribadi anda kepada orang yang tidak dikenal.

Story : Reporter memperingatkan jangan memberikan data pribadi kepada orang yang tidak di kenal di media sosial, dengan diwakili gambar pc, inbox, dan lain sebagainya, gambar tersebut menerangkan data pribadi di media sosial.

Durasi : $02.35-02.41$

Scene 20: Menampilkan gambar kaca pembesar

Audio : Musik.

Story : Gambar kaca pembesar dan tulisan data menggambarkan data pribadi dari pengguna media sosial.

Durasi : $02.42-02.46$

Scene 21: Menampilkan gambar tangan yang memegang smartphone dan tulisan jangan berkomentar dengan bahasa yang bersifat menghina di status orang lain.

Audio : Musik, vokal, jangan berkomentar dengan bahasa yang bersifat menghina, atau menghujat di status orang lain.

Story : Gambar tangan yang memegang smartphone tersebut merupakan perwakilan dari peringatan agar tidak berkomentar yang bersifat menghina status orang di media sosial.

Durasi : $02.47-02.55$

Scene 22: Menampilkan gambar tangan yang memegang smartphone.

Audio : Musik.

Story : Gambar tangan yang memegang smartphone menegaskan kembali untuk tidak berkomentar dengan nada yang menghina di media sosial.

Durasi : $02.56-02.59$

Scene 23: Menampilkan gambar dua individu yang memegang topeng dan tulisan hoax di kepala individu yang kiri, dan tulisan jangan menerima mentah - mentah berita hoax di media sosial.

Audio : Musik, vokal, jangan menerima mentah - mentah berita hoax di media sosial.

Story : Gambar kedua individu tersebut menegaskan bahwa tidak boleh menerima mentah - mentah berita hoax

Durasi : $03.00-03.08$

Scene 24: Menampilkan gambar dengan tulisan hoax.

Audio : Musik.

Story : Menegaskan kembali bahwa jangan merima dengan mentah berita hoax yang ada di media sosial.

Durasi : $03.09-03.11$

Scene 25: Menampilkan gambar tangan yang memegang koran atau majalah dengan tulisan jangan mengklik link atau spam yang terasa aneh di media sosial.

Audio : Musik, vokal, dan yang terakhir jangan mengklik spam atau link yang terasa aneh.

Story : Gambar tangan yang memegang koran dan majalah tersebut memperingatkan bahwa jangan mengklik link atau spam yang terasa aneh di media sosial.

Durasi : $03.12-03.19$

Scene 26: Menampilkan gambar surat dengan tulisan hoax yang berjatuhan kebawah.

Audio : Musik.

Story : Gambar tersebut menegaskan bahwa jangan mengklik link atau spam yang terasa aneh di media sosial.

Durasi : $03.20-03.21$

Scene 27: Menampilkan tulisan akibat terlalu lama menggunakan media sosial.

Audio : Musik, vokal, menggunakan media sosial dapat menyebabkan kecanduan dan mengurangi aktifitas.

Story : Reporter akan menjelaskan akibat terlalu lama menggunakan media sosial.

Durasi : $03.21-03.27$

Scene 28: Menampilkan gambar individu yang menggunakan media sosial.

Audio : Musik, vokal, mengurangi aktifitas fisik.

Story : Gambar tersebut menerangkan bahwa jika terlalu lama menggunakan media sosial dapat mengurangi aktifitas fisik.

Durasi : $03.28-03.29$

Scene 29: Menampilkan gambar individu yang kelelahan dalam menggunakan media sosial.

Audio : Musik, vokal, kelelahan akibat terlalu lama menggunakan media sosial.

Story : gambar individu dengan backgroun logo media sosial untuk menegaskan bahwa individu tersebut kelelahan dalam menggunakan media sosial.

Durasi : $03.30-03.33$ 
Vol.1 No.1 (Mei) 2019, Hal 1-12

Scene 30: Menampilkan gambar reporter dan background dari reporter.

Audio : Musik, vokal, demikian pesan - pesan yang bisa kami sampaikan diharapkan setelah menyimak video ini, penonton lebih hati - hati dalam menggunakan media sosial, sekian dan terimakasih.

Durasi : $03.34-03.53$

\section{Desain}

Ditahap ini penulis menyusun storyboar dengan berdasarkan naskah konsep yang sudah dibuat, berikut storyboard dari video animasi layanan masyarkat bahaya media sosial terhadap remaja :

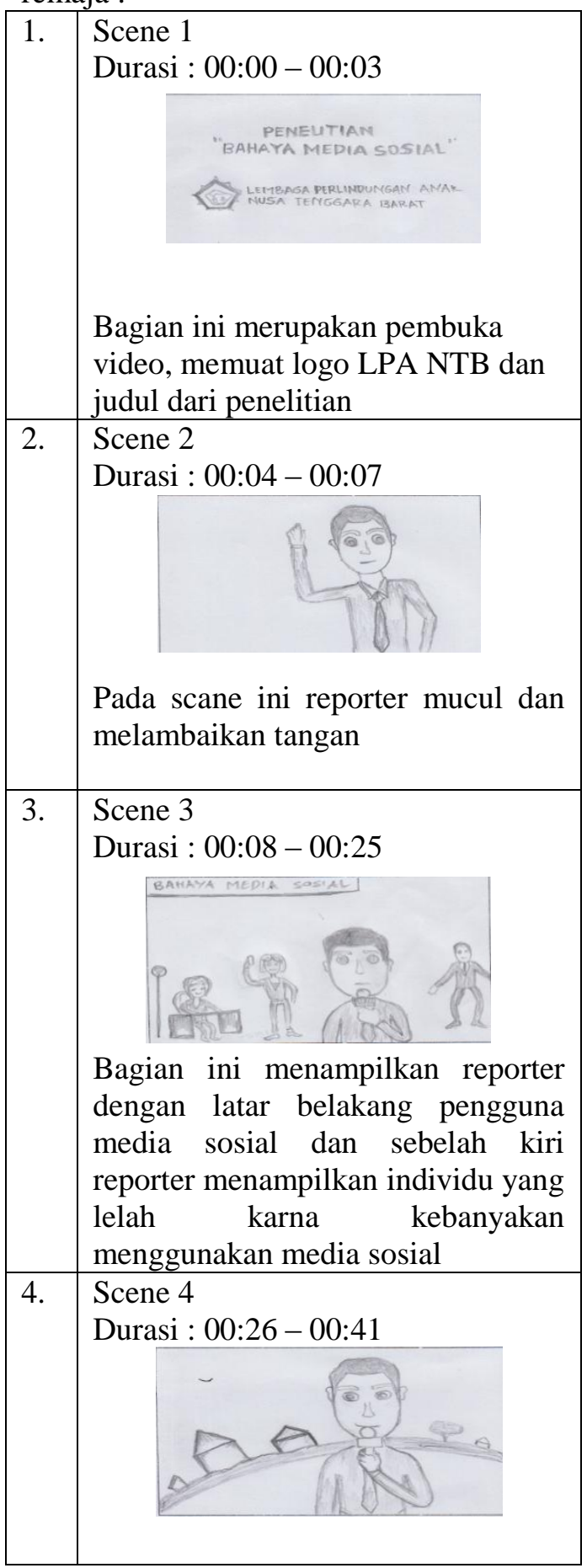

Scane ini memperlihatkan aiasi

reporter untuk pindah ke sesi acara

5. $\quad$ Scene 5

Durasi : 00:42 - 00:45

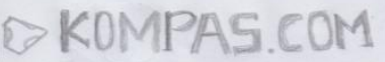

Scane 5 menampilkan logo kompas

6. $\quad$ Scene 6

Durasi : Duration : 00:46 - 00:52

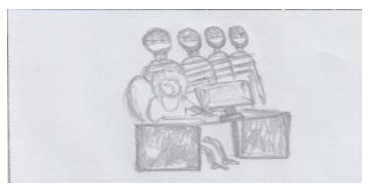

Bagian ini lanjutan dari berita kejahatan media sosial yang dimuat di kompas.com

7. Scene 7

Durasi : 00:53 - 00:55

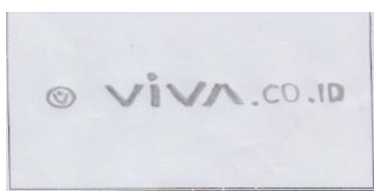

Menampilkan logo viva.co.id

8. $\quad$ Scene 8

Durasi : 00:56 - 01:05

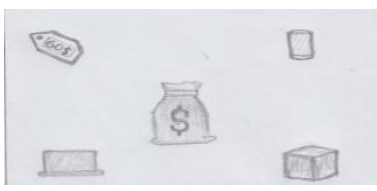

Menampilkan animasi yang melambangkan bahwa barang hasil curian di jual ke group media sosial facebook

9. $\quad$ Scene 9

Durasi : 01:06 - 01:16

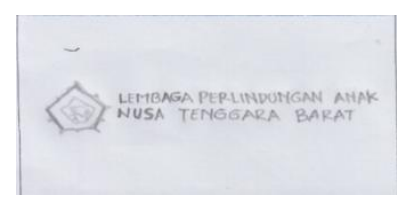

Logo LPA NTB sebagai tempat penelitian penulis 


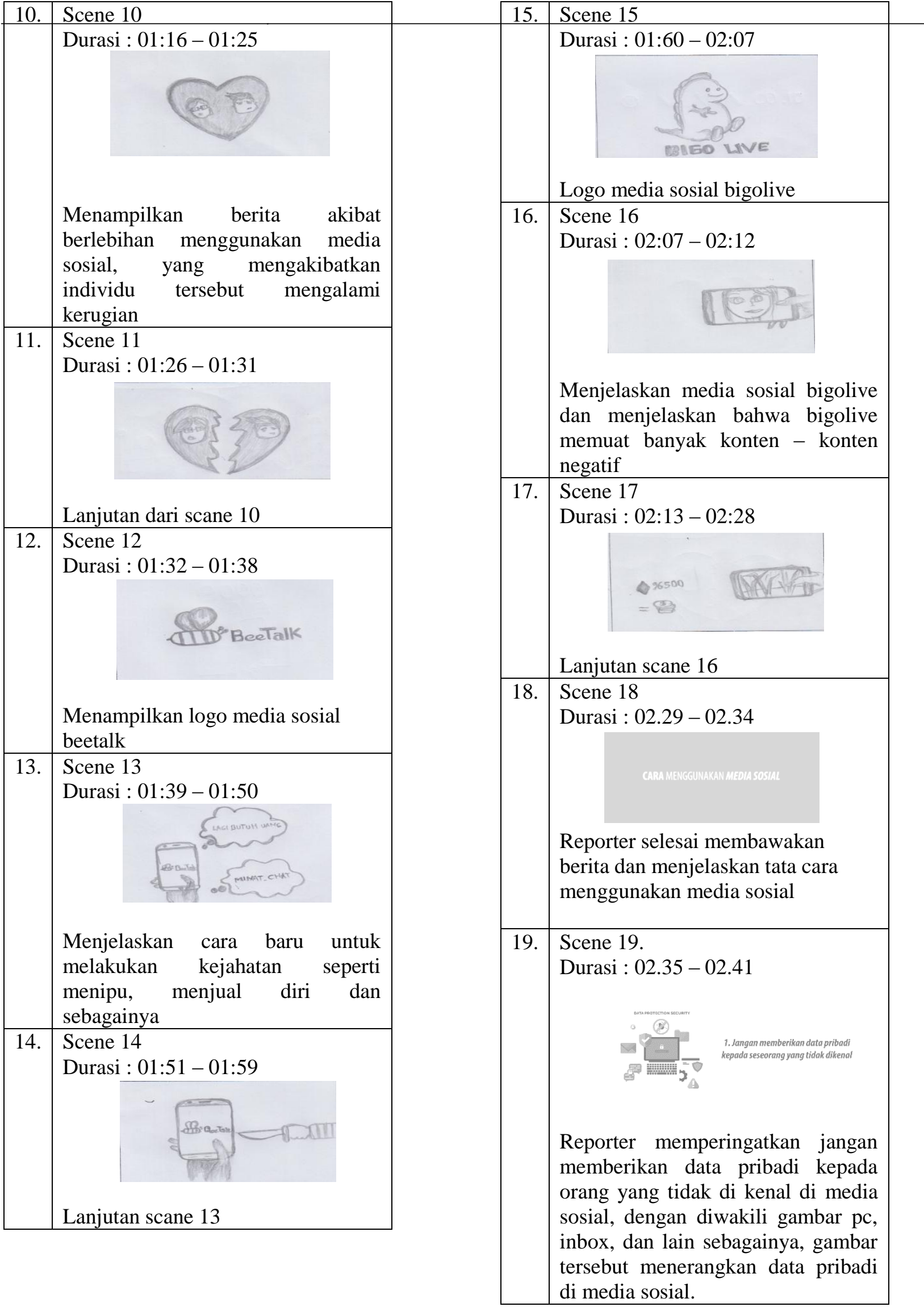


Vol.1 No.1 (Mei) 2019, Hal 1-12

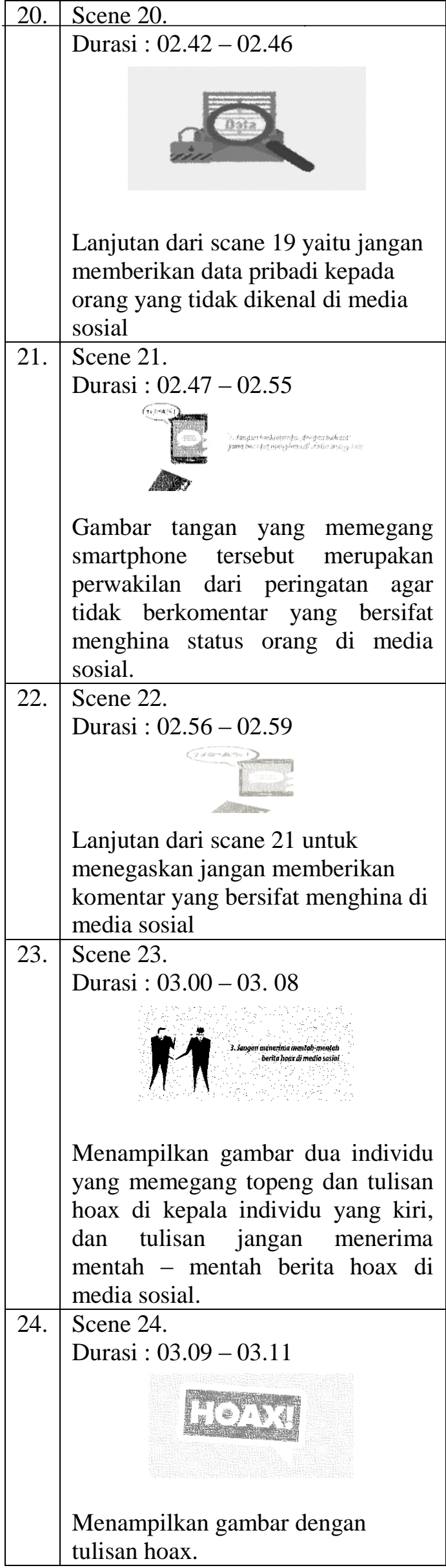

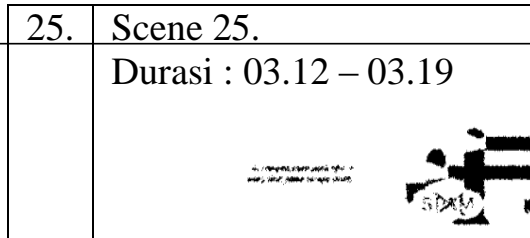

Menampilkan gambar tangan yang memegang koran atau majalah dengan tulisan jangan mengklik link atau spam yang terasa aneh di media sosial.

26. Scene. 26

Durasi : $03.20-03.21$

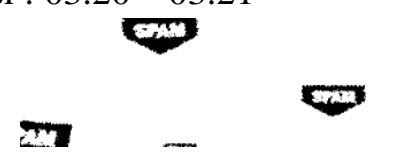

Menampilkan gambar surat dengan tulisan hoax yang berjatuhan kebawah.

27. Scene 27.

Durasi : $03.21-03.27$

Menampilkan tulisan akibat terlalu lama menggunakan media sosial.

28. Scene 28.

Durasi : 03.28 - 03.29

Menampilkan gambar individu yang menggunakan media sosial.

29. Scene 29.

Durasi: 03.30 - 03.33

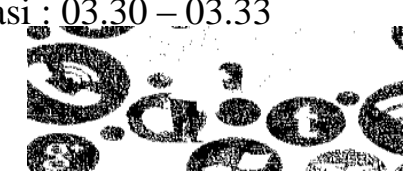

Menampilkan gambar individu yang kelelahan dalam menggunakan media sosial. 


\begin{tabular}{|l|l|}
\hline 30. & Scene 30. \\
\hline Durasi : 03.34-03.53 \\
$\begin{array}{l}\text { Menampilkan gambar reporter dan } \\
\text { background dari reporter. }\end{array}$ \\
\hline
\end{tabular}

\section{Pengumpulan Bahan}

Dalam tahap material colecting atau tahap pengumpulan bahan, penulis data-data berupa file gambar seperti, logo kompas.com, logo viva.co.id, logo LPA NTB, logo beetalk, dan logo bigolive, bahan-bahan tersebut diperlukan dalam pembuatan video animasi, berikut bahan yang sudah penulis kumpulkan:

LEMBAGA PERLINDUNGAN ANAK NUSA TENGGARA BARAT

\section{Gambar 2.1 LPA NTB}

\section{ATD BeeTalk}

Gambar 2.2 Beetalk

\section{KOMPAS.COM}

\section{Gambar 2.3 Kompas.com}

\section{Oviva.co.ID}

\section{Gambar 2.4 viva.co.id}

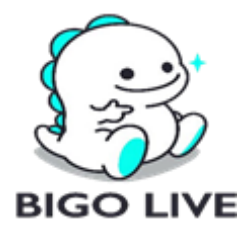

\section{Gambar 2.5 Bigolive}

\section{Tahap Pembuatan}

Dalam tahap assembly atau tahap pembuatan, penulis menyusun bahan dengan adobe photosop cs6, bahan tersebut akan diperlukan dalam tahap pembuatan video animasi layanan masyarakat bahaya media sosia terhadap remaja, penulis menggunakan adobe after effects cs6 untuk memproses bahan yang dikumpulkan menjadi video animasi layanan masyarakat bahaya media sosial terhadap remaja.

\section{Tahap Testing}

Vol.1 No.1 (Mei) 2019, Hal 1-12

Dalam tahap ini penulis melakukan percobaan terhadap video animasi untuk mengetahui apakah video tersebut layak untuk didistribusikan, penulis menggunakan gomplayer untuk memutar video animasi tersebut, berikut sceenshortnya:

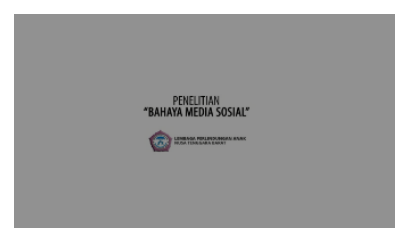

Gambar 2.6 intro

Gambar 2.6, menampilkan intro atau awal dari video dengan menampilkan judul bahaya media sosial dan LPA NTB.

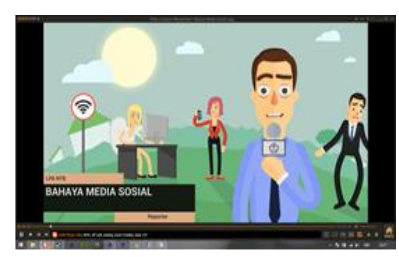

Gambar 2.7 Reporter

Gambar 2.27, menayangkan reporter yang membawakan berita dengan bacground pengguna media sosial, dan individu yang kelelahan akibat menggunakan media sosial.

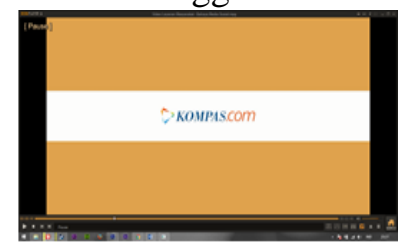

Gambar 2.8 Kompas.com

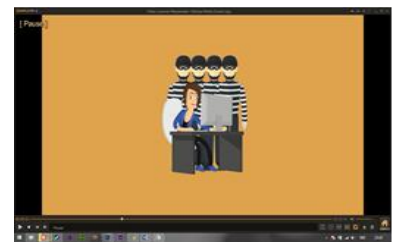

Gambar 2.9 Konten

Gambar 2.8, dan 2.9, menampilkan logo kompas.com dan seorang wanita sedang bermain sosial media di depan pc, lelaki jahat tiba tiba muncul 1 persatu sampai berjumlah 4 orang. 


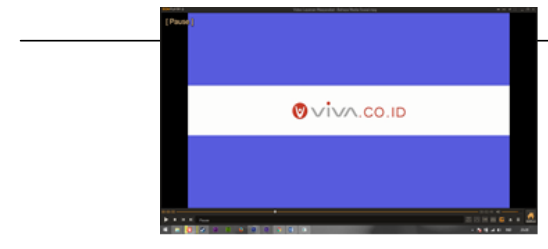

Gambar 2.10 Viva.co.id

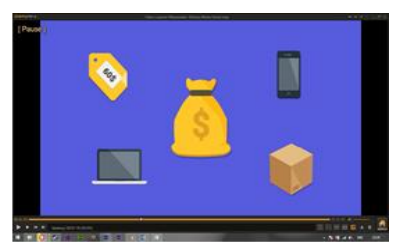

Gambar 2.11 Konten

Gambar 2.10, dan 2.11, menampilkan logo viva.co.id dan memaparkan animasi kejahatan media sosial facebook yang menjual barang hasil curian di group facebook

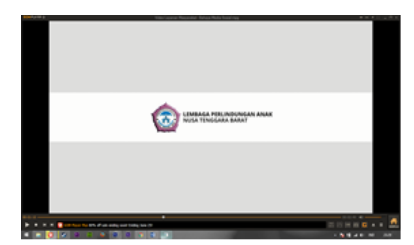

\section{Gambar 2.12 LPA NTB}

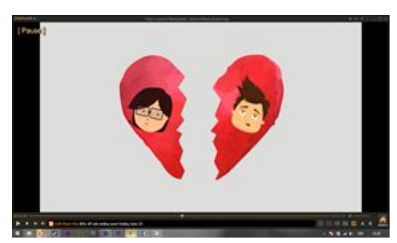

\section{Gambar 2.13 Konten}

Gambar 2.12, dan 2.13, menampilkan logo LPA NTB dan Muncul gambar hati yang melambangkan individu yang sedang berpacaran, sebelah kiri wanita dan sebelah kanan pria

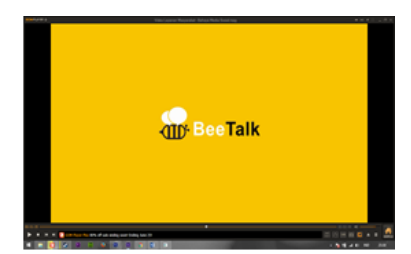

\section{Gambar 2.14 Beetalk}

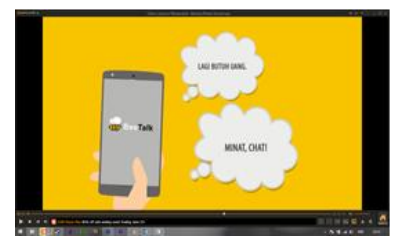

Vol.1 No.1 (Mei) 2019, Hal 1-12

\section{Gambar 2.15 Konten}

Gambar 2.14, dan 2.15, Menampilkan logo beetalk dan individu yang mengakses smartphone yang menayangkan caption seperti "lagi butuh uang", "minat chat".

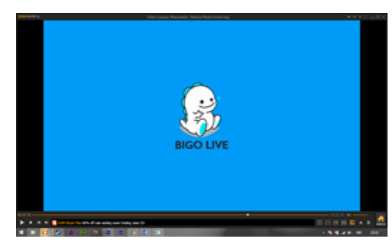

Gambar 2.16 Bigolive

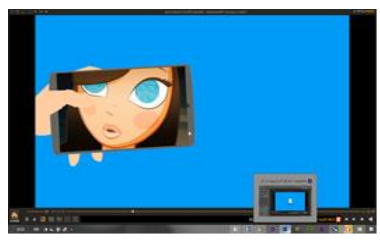

\section{Gambar 2.16 Konten}

Gambar 2.15, dan 2.16, menayangkan individu yang mengakses bigolive dan Dari sisi kanan muncul smartphone yang di layarnya ada gambar seorang wanita dan tangan yang memegang smartphone seolah olah sedang menonton live streaming

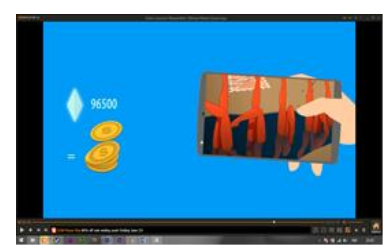

\section{Gambar 2.17 Konten}

Gambar 2.17, menampilkan individu yang mengakses bigolive di smartphonenya, uang logam dan berlian Smartphone yang menampilkan live streaming gambar erotis dan di sisi kiri uang dan berlian yang didapatkan dari memamerkan bagian tubuh tertentu

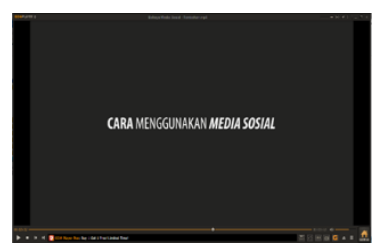

Gambar 2.18 Judul

Gambar 2.18, menampilan tulisan "cara menggunakan media sosial". 


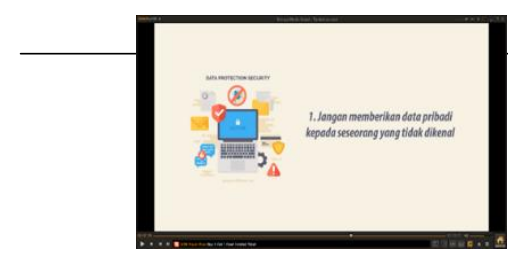

Gambar 2.19 Data

Gambar 2.19, menampilkan tulisan jangan memberikan data pribadi ke orang yang tidak dikenal di media sosial

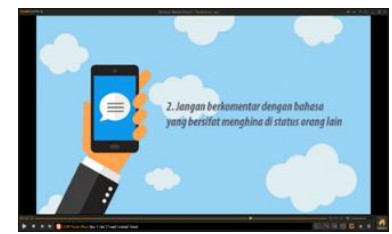

\section{Gambar 2.20 Komentar}

Gambar 2.20 menegaskan untuk tidak berkomentar kasar dan menghina di status orang lain.

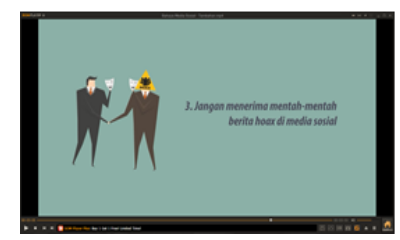

Gambar 2.21 Individu

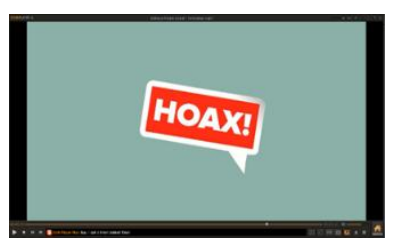

Gambar 2.22 Hoax

Gambar 2.21, dan 2.22, menampilkan pesan untuk tidak menerima mentah-mentah berita palsu di media sosial

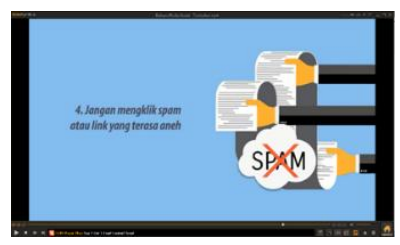

Gambar 2.23 Spam

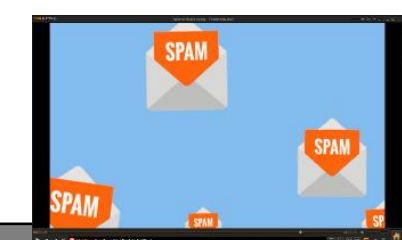

\section{Gambar 2.24 Spam}

Gambar 2.23, dan 2.24, menampilkan pesan untuk tidak mengklik link atau spam yang terasa aneh.

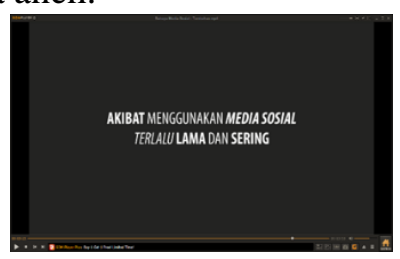

\section{Gambar 2.25 Dampak}

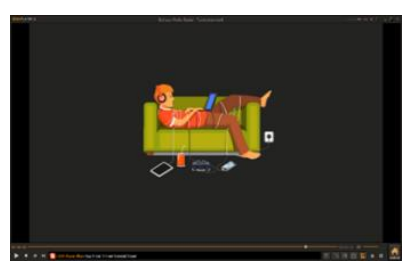

Gambar 2.26 Konten

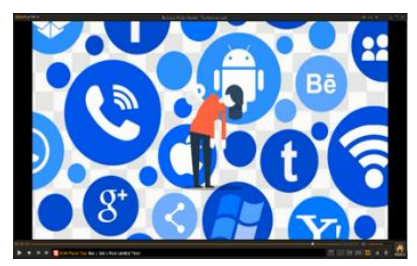

\section{Gambar 2.27 Konten}

Di gambar 2.25, 2.26 dan 2.27, menampilkan akibat dari terlalu lama menggunakan media sosial seperti mengurangi aktifitas fisik, dan menyebabkan rasa malas.

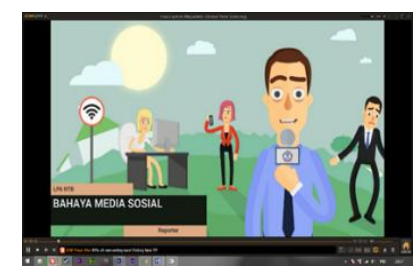

Gambar 2.28 Reporter

Gambar 2.28, menampilkan gambar reporter yang menandakan bahwa berita selesai dibawakan dan menyampaikan pesan ajakan agar lebih hati - hati dalam menggunakan media sosial.

\subsection{Tahap Distribusi}

Di tahap distribusi, penulis mengemas video dalam bentuk cd-drive untuk di berikan kepada 
pihak LPA NTB untuk digunakan sebagai media sosialisasi bahaya media sosial kepada masyarakat khususnya remaja dan penulis mengupload di media sosial seperti youtube, facebook, twitter dan sebagainya.

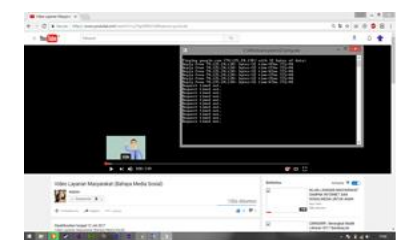

\section{Gambar 2.29 Viewer youtube}

Gambar 2.29, berdasarkan hasil viewer dari video yang di upload di youtube jumlah viewer yang didaptkan adalah 160 viewer.

\section{HASIL DAN PEMBAHASAN}

Dalam hasil dan pembahasan penulis menggunakan skala likert untuk mengukur hasil dari kuesioner yang dibagika secara manual, dan menggunakan googlefom untuk kuesioner online.berikut hasil hitungan dari

\section{Skala Likert}

Bobot nilai : $a=5, b=4, c=3, d=2, e=1$, dan nilai 1 sampai 5 jika dipersenkan : $1=0 \%$ $19,99 \%, 2=20 \%-39,99 \%, 3=40 \%-59,99 \%$, $4=$ $60 \%-79,99 \%, 5=80 \%$ - 100\%. Dan pilihan ganda di singkat dengan : sangat setuju= SS, setuju $=S$, Netral $=N$, tidak setuju $=$ TS, tidak sangat setuju $=\mathrm{TSS}$.

Dari 35 orang responden yang dikumpulkan penulis mendapat jawaban sebagai berikut, dalam langkah ini responden yang menjawab pertanyaan 1 sampai 5 digabungkan dan dikalikan dengan nilai jawaban yang dipilih :

$\mathrm{SS}(5)=10 * 5=50$

$\mathrm{S}(4)=17 * 4=68$

$\mathrm{N}(3)=7 * 3=21$

$\operatorname{TS}(2)=1 * 2=2$

$\operatorname{TSS}(1)=0 * 1=0$

Langkah selanjutnya menambahkan hasil dari perkalian untuk mendapatkan total skor , $50+68+21+2+0=141$, jadi total skor adalah 141. Di metode skala likert rumus item penilaian sbb:

$\mathrm{Y}=$ skor tertinggi likert $*$ jumlah responden $(5$ "melambangkan nilai tertinggi yaitu $80 \%$ $100 \% "), X=$ skor terendah likert $*$ jumlah responden (1 "melambangkan nilai terendah yaitu $0 \%$ - 19,99\%). Langkah selanjutnya jumlah skor tertinggi untuk item sangat setuju dikalikan dengan jumlah responden : 5"nilai tertinggi" * 35 "jumlah responden" $=175$, begitu juga dengan item sangat tidak setuju dilakukan seperti langkah diatas : 1"nilai terendah" * 35 "jumlah responden" $=35$, jika total skor dari responden adalah 141 maka penilaian interpretensi responden terhadap video animasi layanan masyarakat bahaya media sosial tersebut adalah hasil yang di dapatkan dengan menggunakan, rumus index $\%=$ total skor $/ \mathrm{Y} *$ 100. Maka : 141 / 180 "nilai tertinggi 80\%$100 \%$ di tambah menjadi $180 \%$ di rumus index" $* 100=78,33 \%=79 \%$ "setelah dibulatkan dari 78,33\%", 79\% merupakan kategori setuju di skala likert. Dari hasil di atas dapat disimpulkan bahwa responden yang berjumlah 35 orang setuju dengan pertanyaan yang berkaitan dengan video animasi layanan masyarakat bahaya media sosial terhadap remaja.

\section{Googleform}

Selain menggunakan skala likert, penulis menggunakan googleform yang adi di googledrive untuk menjawab pertanyaan kuesioner setelah menonton video yang di upload di youtube, berikut sceenshortnya:

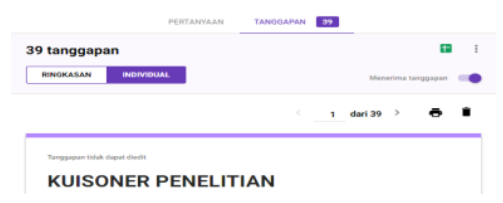

\section{Gambar 3.1 Tanggapan Responden}

Di gambar 3.1, penulis mendapatkan hasil dari kuesioner yang dibagikan menggunakan googleform dan 39 tanggapan yang penulis dapatkan.

\section{SIMPULAN DAN SARAN}

\section{Simpulan}

Dari pembahasan yang telah diuraikan dan berdasarkan hasil uji coba, maka penulis dapat menarik kesimpulan sebagai berikut:

1. Pengembangan dari alat sosialisasi LPA NTB yang selama ini masih menggunakan cara lama berhasil di perbaharui khususnya dalam sosialisasi yang berkaitan dengan masalah bahaya media sosial.

2. Video layanan masyarakat bahaya media sosial terhadap remaja, berdasarkan hasil kuisioner yang telah di sebarkan ke responden dapat membantu memberikan informasi dan pemahaman dalam menggunakan media sosial, dengan persentase setuju yaitu $70 \%$. 
Berdasarkan paparan penulis pada beberapa bab sebelumnya, penulis menyadari bahwa penelitian ini masih jauh dari kata sempurna, sehingga penulis menyampaikan beberapa saran agar penelitian ini bisa menjadi lebih baik

1. LPA NTB menyarankan, konten media sosial beetalk dan bigolive disamarkan agar penonton yang belum mengetahui media sosial tersebut tidak terpancing untuk mencoba media sosial beetalk dan bigolive.

2. Transisi atau pergerakan video masih kaku.

3. Karakter dalam animasi kurang beragam..

4. Seiring dengan perkembangan teknologi informasi, diharapkan video ini dapat dikembangkan agar penonton lebih bisa menerima dan memberikan hiburan di selain memberikan pengetahuan.

Demikian kesimpulan dan saran dari penulisan penelitian ini, agar bermanfaat bagi semua pihak. Masukan yang bersifat membangun sangat dibutuhkan untuk dapat meyempurnakan skripsi ini.

\section{UCAPAN TERIMAKASIH}

Dengan selesainya penelitian ini, maka penulis ingin mengucapkan terima kasih kepada pihak-pihak yang telah banyak membantu dalam menyelesaikan penelitian ini. Dalam kesempatan ini penulis menyampaikan ucapan terimakasih kepada:

1. Ibu Komariyuli Anwariyah, S.T., M.Kom., selaku Ketua Sekolah Tinggi Manajemen Informatika dan Komputer (STMIK) Bumigora Mataram.

2. Ibu Ni Gusti Ayu Dasriani, M.Kom., selaku Ka. Prodi S1 Teknik Informatika.

4. Bapak Danang Tejo Kumoro, M.Kom selaku dosen pembimbing.

5. Untuk Ibu dan ayah tercinta yang telah memberikan dukungan moril dan dukungan materi serta mendoakan, memberikan semangat dalam penyusunan penelitian ini.

6. Teman-teman Mahasiswa Bima Dompu STMIK Bumigora Mataram, dan semua teman-teman yang tidak bisa disebutkan satu persatu, atas semua bantuannya baik secara langsung maupun tidak langsung dan selalu memberi semangat.

\section{REFERENSI}

[1] Binanto, Iwan. 2010. Multimedia DigitalDasar Teori dan Pengembangannya. Yogyakarta: CV Andi Offset (Penerbit Andi).

[2] Setiawan, Dirgayuza, 2008. Gaul Ala Facebook Untuk Pemula. Jakarta: Media Kita.

[3] https://kominfo.go.id/, (diakses ulang tanggal 25 Juli 2017 09.40WIB

[4] http://regional.kompas.com/, (di akses ulang tanggal 25, Juli 2017, 10.00 WIB)

[5] http://www.viva.co.id, (di akses ulang tanggal 25 Juli 2017 11.00 WIB) 